\title{
Chlorophyll biosynthesis and epidermal characteristics of the leaves of a variegated variety vs. all-green variety of Chlorophytum capense
}

\author{
Y.Q. ZHAO*, L.H. DONG*, B. HUANG*, C.B. DING*, Y.E. CHEN*, Z.W. ZHANG**, Y. JIANG***, \\ S. YUAN ${ }^{* *}$, and M. YUAN ${ }^{*}+$ \\ College of Life Science, Sichuan Agricultural University, 625014 Ya'an, China* $^{*}$ \\ College of Resources, Sichuan Agricultural University, 611130 Chengdu, China** \\ Horticulture Research Institute, Sichuan Academy of Agricultural Sciences, 610066 Chengdu, China***
}

\begin{abstract}
Chlorophytum capense var. medio-pictum is widely used as a houseplant with its central yellowish white stripe in green leaves. This study investigated chlorophyll biosynthesis, and epidermal characteristics in leaf stripes of different color. The results showed that yellowish white leaf stripes (YS) have a lower 5-aminolevulinic acid (ALA) content than that of green stripes. Meanwhile, YS had higher coproporphyrinogen III (Coprogen III) and Mg-protoporphyrin monomethyl ester (Mpe) contents, but the lower content of protoporphyrinogen IX (Proto IX) and protochlorophyllide (Pchlide) compared to green stripes, suggesting that the occurrence of yellowish white stripes may be attributed to the blocked ALA synthesis and the inhibited conversions from Coprogen III to Proto IX and Mpe to Pchlide. In addition, the upper and lower epidermal cells in YS were larger than those in green stripes. The chloroplasts developed normally in the guard cells of the YS epidermis, though almost no chloroplasts were detected in YS mesophyll cells.
\end{abstract}

Additional key words: chlorophyll metabolic intermediates; epidermal micro-morphological characteristics; stomatal characteristics; variegated spider plant.

\section{Introduction}

Chlorophylls (Chl), the essential pigment molecules bound to photosynthetic proteins in the thylakoid membrane, are responsible for harvesting solar energy and charge separation and electron transport via reaction centers (Tanaka and Tanaka 2006). To maintain healthy growth, plants have evolved efficient strategies to control the entire Chl biosynthetic pathway that is executed via a series of cooperative reactions catalyzed by numerous enzymes (Masuda and Fujita 2008). Chl biosynthesis from glutamyl-tRNA ${ }^{\text {Glu }}$ (Glu-tRNA) to Chl $b$ involves at least 15 enzymes encoded by 27 genes in Arabidopsis and there are 14 major intermediates in this pathway (Beale 2005). Chl biosynthesis can be classified into three phases (Yuan et al. 2017). The first phase includes the synthesis of protoporphyrin IX (Proto IX) from Glu-tRNA. 5-aminolevulinic acid (ALA) biosynthesis is the ratelimiting step in this phase. The second phase is the synthesis of Chl $a$ from Proto IX. At this point, the insertion of $\mathrm{Fe}^{2+}$ into porphyrin nucleus initiates the heme pathway, but the insertion of a central $\mathrm{Mg}^{2+}$ into the porphyrin ring forms Mg-protoporphyrin IX (Mg-Proto IX), which is the key step catalyzed by Mg-chelatase. In addition, chlorophyllide biosynthesis is a strictly light-dependent pathway catalyzed by NADPH-protochlorophyllide oxidoreductase (POR) in angiosperms and is also one of the key steps in the Chl biosynthesis. The third phase is the interconversion between $\mathrm{Chl} a$ and $\mathrm{Chl} b$, which is known as the Chl cycle (Rüdiger 2002). Disruption of any step of Chl biosynthesis might cause leaf color changes. Chldeficient mutants reduce the $\mathrm{Chl}$ content, and finally inhibit chloroplast development (Zhang et al. 2006), and synchronously, the leaves exhibit different phenotypes, such as etiolation (Liu et al. 2008), chlorina (Jung et al. 2003), pale green (Nakanishi et al. 2005), and yellowish green (Zhang et al. 2006).

Furthermore, blocked Chl biosynthesis directly impacts the accumulation of photosystem reaction core proteins in the thylakoid membrane and represses the assembly of PSs, resulting in the inhibition of chloroplast development (Plumley and Schmidt 1995). In addition, the lack of detectable chloroplasts and Chls are the major cause of developmental abnormalities in the Arabidopsis crl mutant (Chen et al. 2009). In the Chl-less golden-leaf privet, the upper golden leaves and lower green leaves showed

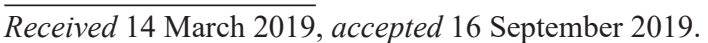

${ }^{+}$Corresponding author; e-mail: yuanming@ sicau.edu.cn

Abbreviations: ALA - 5-aminolevulinic acid; Car - carotenoids; Chl - chlorophyll; Chlide - chlorophyllide; Coprogen III coproporphyrinogen III; FM - fresh mass; $F_{v} / F_{m}$ - maximal quantum yield of PSII photochemistry; GC - green leaf center; GE - green leaf edge; GS - green leaf stripe; Mg-Proto IX - Mg-protoporphyrin IX; Mpe - Mg-protoporphyrin monomethyl ester; NPQ - nonphotochemical quenching; PBG - porphobilinogen; Pchlide - protochlorophyllide; POR - NADPH-protochlorophyllide oxidoreductase; Proto IX - protoporphyrin IX; Urogen III - uroporphyrinogen III; YS - yellowish white leaf stripe.

Acknowledgements: This research was supported by Sichuan Agricultural University. 
different Chl and precursor content (Yuan et al. 2010) and the leaf structures of the golden leaves and the green leaves are also apparently different (Yuan et al. 2014).

Plants with variegated leaves are usually used as ornamental garden plants. Variegated leaves have attracted much more attention to explore the mechanism of their chloroplast biogenesis and photosynthesis in the past decade. Chlorophytum capense var. medio-pictum is an indoor ornamental plant displaying an interesting pattern of color distribution on the leaf surface. Chlorophytum capense var. medio-pictum, with a central yellowish white stripe in the green leaves, is a cultivar of Chlorophytum capense (L.) Kuntze, whose leaves are completely green without stripes. Jia et al. (2013) showed that the different leaf color is correlated with the different Chl content and the central stripe contains much less Chls than that of the green part. The leaf anatomical structure observed in paraffin slices also presented large differences between different parts of $C$. capense var. medio-pictum leaf stripes (Jia et al. 2011).

C. capense var. medio-pictum has a yellowish white central stripe and the edges of the leaves are green. The different-color stripes accumulate different content of Chls. The goal of this study was to explore the differences in Chl biosynthesis between different-color leaf stripes, to analyze the putative blocked steps in Chl biosynthesis in YS, and to investigate further the differences in epidermal and stomatal characteristics in different-color leaf stripes. Therefore, key Chl metabolic intermediates in different leaf color tissues were measured, and epidermal and stomatal characteristics were investigated as well.

\section{Materials and methods}

Plant material and growth conditions: Chlorophytum capense var. medio-pictum and Chlorophytum capense plants grew on soil in greenhouse for 2 years under the condition of 14-h light [PAR of $120 \mu \mathrm{mol}$ (photon) $\mathrm{m}^{-2} \mathrm{~s}^{-1}$ ]/ 10 -h darkness at $25^{\circ} \mathrm{C}$ and $60 \%$ relative humidity. Similar healthy plants were selected and the middle parts of the third leaves from the top were used for measurements. The leaves of $C$. capense var. medio-pictum were divided into the green leaf stripe (GS) and the yellowish white leaf stripe (YS) according to the leaf color. The leaves of $C$. capense were also divided into the green leaf edge (GE) and the green leaf center (GC) according to the zone that is roughly comparable to $C$. capense var. medio-pictum (Fig. 1).

Chl and Chl precursor content: Chls were measured according to Porra et al. (1989) and carotenoids (Car) were detected by the method of Lichtenthaler and Wellburn (1983). In brief, 0.1-g leaf sample was extracted with $80 \%$ acetone stored at $4^{\circ} \mathrm{C}$ and the content of Chl $a$, Chl $b$, and Car was determined at 663, 646, and $470 \mathrm{~nm}$ using a UV-1800 spectrophotometer (Shimadzu, Japan). 5-aminolevulinic acid (ALA), porphobilinogen (PBG), uroporphyrinogen (Urogen III), coproporphyrinogen III (Coprogen III), protoporphyrin IX (Proto IX), Mg-protoporphyrin IX (Mg-proto IX), Mg-protoporphyrin mono- methyl ester (Mpe), protochlorophyllide (Pchlide), chlorophyllide $a$ (Chlide) and Chlide $b$ were all determined according to the methods described by Smith and Witty (2002).

Chlorophyll fluorescence images were performed with a modulated imaging fluorometer (Imaging PAM M-Series, Heinz Walz Instruments, Effeltrich, Germany). After adaption in the dark for $30 \mathrm{~min}$, the maximal quantum of PSII photochemistry $\left(\mathrm{F}_{\mathrm{v}} / \mathrm{F}_{\mathrm{m}}\right)$ and nonphotochemical quenching (NPQ) were imaged and calculated (Chen et al. 2016).

Protein extraction: Plastid proteins were isolated according to the protocol described previously (Fristedt et al. 2010). Each part of the leaves was homogenized in icecold solution A (25 mM Tricine, pH 7.8, $330 \mathrm{mM}$ sorbitol, $1 \mathrm{mM}$ EDTA, $10 \mathrm{mM} \mathrm{KCl}, 0.15 \%$ bovine serum albumin, $4 \mathrm{mM}$ sodium ascorbate, $7 \mathrm{mM}$ L-cysteine) and filtered through four layers of nylon mesh. The filtrate was centrifuged at $4^{\circ} \mathrm{C}$ for $3 \mathrm{~min}(1,000 \times g)(S T 16 R$, Thermo Fisher, Germany) and resuspended in the same buffer to wash the plastids and centrifuged at $4^{\circ} \mathrm{C}$ for $3 \mathrm{~min}$ $(1,000 \times g)$. Then, the plastid pellet was resuspended in solution $\mathrm{B}$ (10 mM Tricine, $5 \mathrm{mM} \mathrm{MgCl}_{2}, 10 \mathrm{mM} \mathrm{NaF}$ ) and lysed for $10 \mathrm{~min}$ in the dark on ice. After that, the suspension was centrifuged at $6,000 \times g$ for $5 \mathrm{~min}$. The pellet was gently resuspended in solution $\mathrm{C}(100 \mathrm{mM}$ sorbitol, $25 \mathrm{mM}$ Tricine, $\mathrm{pH} 7.8,5 \mathrm{mM} \mathrm{MgCl}, 10 \mathrm{mM}$ $\mathrm{KCl}, 10 \mathrm{mM} \mathrm{NaF}$ ) and centrifuged at $6,000 \times g$ for $5 \mathrm{~min}$, and finally resuspended in a small volume of the same buffer. The protein content was determined according to Bradford (1976).

SDS-PAGE and immunoblotting analysis: Plastid proteins were separated by sodium dodecylsuplhate polyacrylamide gel electrophoresis (SDS-PAGE) at $4^{\circ} \mathrm{C}$ for $4 \mathrm{~h}$ (Bio-Rad, Hercules, USA) as described by Fristedt et al. (2010) and then stained with Coomassie Brilliant Blue. For immunoblotting analysis, SDS-PAGE gel was electroblotted to PVDF membrane as described by Chen et al. (2016). Then, the membranes were incubated with anti-Lhca1, anti-PsaD, anti-PsbA (D1), and anti-PsbD (D2) primary antibodies (Agrisera, Umea, Sweden). The secondary antibody used was the horseradish peroxidase-conjugated antibody (Bio-Rad, Hercules, USA). A chemiluminescent detection system (ECL, GE Healthcare, Buckinghamshire, UK) was used to perform the immunoblotting. The quantification of immunoblots was done using Quantity One software (Bio-Rad, Hercules, USA).

Analysis of leaf characteristics: Epidermal characteristics were observed by a light microscope (CL-L, Nikon, Tokyo, Japan) by the nail polish imprint method (Berger and Altmann 2000). The upper and lower epidermal cells parameters, including the cell length, width, size, and density, and stomatal parameters including stomatal length, width, size, density, and index, were observed by microscopy and counted using Image-Pro Plus 6.3 image 
analysis system (Media Cybernetics Inc., Rockville, USA). The stomatal index (SI) was calculated by the formula: $\mathrm{SI}=\mathrm{S} /(\mathrm{S}+\mathrm{E})$, where $\mathrm{S}$ represents the stomatal number per unit area and $\mathrm{E}$ is the epidermal cell number per unit area (Horiguchi et al. 2006). Fifty cells were measured for all the parameters under the microscope and five microscope views were randomly selected in each slide.

In order to observe plastids in the mesophyll cells, leaf tissue was ground in distilled water with a mortar, and $10 \mu \mathrm{L}$ of homogenate was dripped onto a glass slide. Then, chloroplasts were imaged with a fluorescence microscope (BX53, Olympus Corporation, Tokyo, Japan) coupled with DP71 imaging system (Olympus Corporation, Tokyo, Japan). For measuring stomata, in situ fluorescence imaging of stomatal chlorophylls was applied (FITC, EX465-495, DM505, BA515-555) after closing the bright field.

Statistical analysis: All experiments were repeated at least three times and expressed as mean \pm standard deviation (SD). Student's t-test or Duncan's multiplication range test were used to locate differences. All analyses were done with SPSS 20.0 (IBM, Chicago, USA) and $p<0.05$ was regarded as significant.

\section{Results}

Phenotypic traits and the photosynthetic pigment content: The leaf of $C$. capense var. medio-pictum exhibits a different phenotype from C. capense (Fig. 1A). C. capense var. medio-pictum showed a yellowish white stripe in the leaf center, which was named as the yellowish white leaf stripes (YS), and the green part in the leaf edge, which was named as the green leaf stripe (GS) in this paper. But the leaf of $C$. capense was all green from the edge (GE) to the center (GC).

To explore the mechanism for the occurrence of the yellowish white stripes in $C$. capense var. medio-pictum, the content of Chl $a$, Chl $b$, and Car was measured. As shown in Fig. $1 B$, Chls and Car content of GS was similar to the GC and GE parts. However, $\mathrm{Chl} a$ and $\mathrm{Chl} b$ and $\mathrm{Car}$ content of YS was much lower than that of GS, GC, and GE. The Chl $a$ and Chl $b$ content of YS was lesser than 5\% of the green part, and the Car content was lesser than one quarter of GS, GC, and GE. The $\mathrm{Chl} a / b$ ratio of YS was about 3.5, while the ratios of GS, GC, and GE were about 4.0. The Chls/Car ratio of YS was only 0.8 , while these ratios of GS, GC, and GE were about 4.0. The difference of Chl $a / b$ ratio between the yellowish white part and the green part was relatively small, but the difference of Chls/Car ratio between the yellowish white part and the green part was large. Therefore, the low Chl content and low ratio of Chls to Car might be the main reason for the formation of the yellowish white leaf stripes in $C$. capense var. medio-pictum.

We also detected the $\mathrm{Chl}$ fluorescence of $C$. capense var. medio-pictum and C. capense leaves (Fig. 1S, supplement). The $\mathrm{Chl}$ fluorescence parameters of $\mathrm{F}_{\mathrm{v}} / \mathrm{F}_{\mathrm{m}}$ and NPQ were slightly lower in the YS part compared to those in the green parts. But there was no difference in $\mathrm{F}_{\mathrm{v}} / \mathrm{F}_{\mathrm{m}}$ values between GS, GC, and GE.

Characterization of $\mathbf{C h l}$ biosynthesis: The content of the representative key precursors in Chl biosynthesis was analyzed. As shown in Fig. 2, ALA synthesis in YS was suppressed and its content was below $50 \%$ of that in GS, GC, or GE parts. The PBG content in YS did not differ obviously from the other three parts. Urogen III content in YS was similar to GC and GE, slightly lesser than that in GS. Meanwhile, the content of Coprogen III in YS was higher than that of the others, while the content of Proto IX was much lower than that in the other parts. For the second phase of biosynthesis, Mg-proto IX content in YS was only half of the GS or GC. YS accumulated a higher amount of Mpe than that of the other three parts, but the content of Pchlide, Chlide $a$, and Chlide $b$ in YS was lower. Taken together, the formation of the yellowish white leaf stripes in C. capense var. medio-pictum might be partially attributed to the blocked synthesis of ALA and the inhibited conversions from Coprogen III to Proto IX and from Mpe to Pchlide.

Features of plastids: The pigments and thylakoid membrane proteins are responsible for the assembly of the photosystems that is a precondition of chloroplast biogenesis. SDS-PAGE of the plastid proteins showed that the proteins which were lesser than $50 \mathrm{kD}$, including the main photosynthesis-related proteins, such as CP43 (about
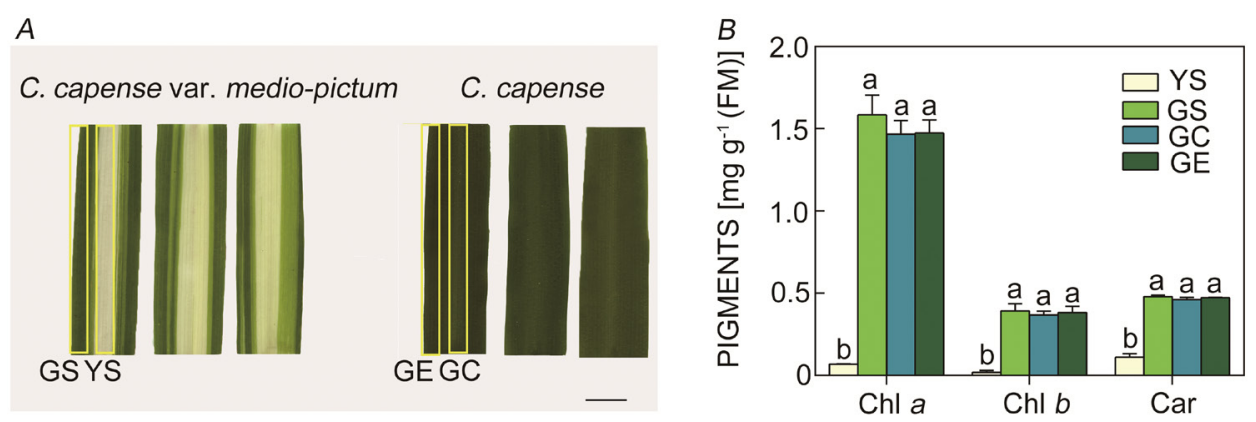

Fig. 1. The phenotype of Chlorophytum capense var. medio-pictum and $C$. capense $(A)$ and their photosynthetic pigments content $(B)$. Error bars represent standard deviations of three independent experiments. Different letters depict significant differences according to Duncan's multiple range tests at $P<0.05$. Chl $a$ - chlorophyll $a$; Chl $b$ - chlorophyll $b$; Car - carotenoids; FM - fresh mass; YS - yellowish white leaf stripe; GS - green leaf stripe; GC - green leaf center; GE - green leaf edge. Black scale bar represents $1 \mathrm{~cm}$. 


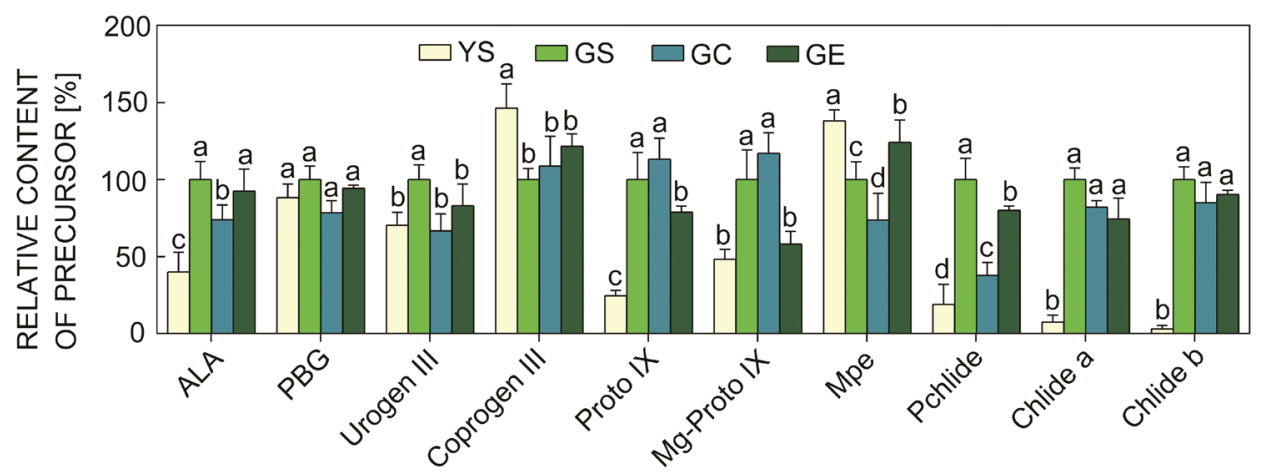

Fig. 2. The relative content of chlorophyll precursors in Chlorophytum capense var. medio-pictum and C. capense plants. The precursors relative content in the GS part was defined as $100 \%$. Error bars represent standard deviations of three independent experiments. Different letters depict significant differences according to Duncan's multiple range tests at $P<0.05$. ALA - 5-aminolevulinic acid; PBG - porphobilinogen; Urogen III - uroporphyrinogen; Coprogen III - coproporphyrinogen III; Proto IX - protoporphyrin IX; Mg-proto IX - Mg-protoporphyrin IX; Mpe - Mg-protoporphyrin monomethyl ester; Pchlide - protochlorophyllide; Chlide $a$ chlorophyllide $a$; Chlide $b$-chlorophyllide $\mathrm{b}$; Chl - chlorophyll; Chl $a$-chlorophyll $a$; Chl $b$ - chlorophyll $b$. YS - yellowish white leaf stripe; GS - green leaf stripe; GC - green leaf center; GE - green leaf edge.

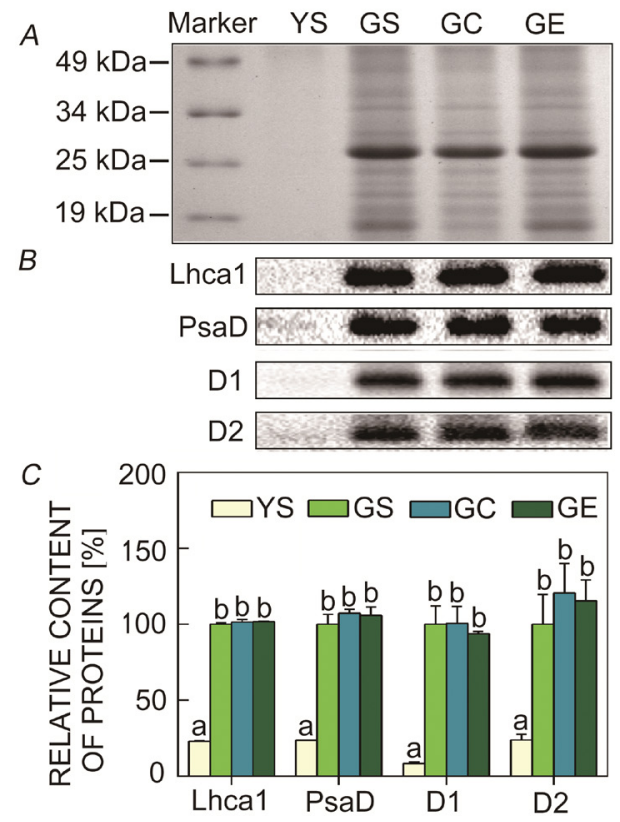

Fig. 3. The thylakoid membrane proteins in Chlorophytum capense var. medio-pictum and C. capense plants. (A) SDS-PAGE of thylakoid membrane proteins after Coomassie Blue staining. $(B)$ Immunoblotting was performed with antibodies against Lhca1, PsaD, D1, and D2 proteins. $(C)$ The relative quantification of immunoblots. Loading was according to an equal amount of protein. Error bars represent standard deviations of three independent experiments. Different letters depict significant differences according to Duncan's multiple range tests at $P<0.05$. YS - yellowish white leaf stripe; GS - green leaf stripe; GC green leaf center; GE - green leaf edge.

$43 \mathrm{kD}$ ), CP47 (about $47 \mathrm{kD}$ ), LHCIs (about 20-23 kD), and LHCIIs (about 23-30 kD), were markedly reduced in YS when comparing with the other parts (Fig. $3 A$ ). Lhca1, PsaD, D1, and D2 proteins were abundant in the three green parts and showed no significant difference.
By contrast, the content of Lhca1, PsaD, D1, and D2 was much lower in YS than in the other parts (Fig. 3B,C).

As shown in Fig. 4, the bright-field images revealed typical chloroplasts in the green parts, but only leucoplasts and no chloroplasts could be found in the YS part. Moreover, Chl fluorescence in YS could hardly be observed (Fig. 4). These results suggested that the limitation of Chl biosynthesis reduced the accumulation of photosynthetic proteins and further stunted chloroplast biogenesis.

Characteristics of epidermis: To ascertain whether the epidermis development in YS also differs from the GS, GC, and GE parts, we analyzed the epidermal cell size and density (Fig. 5). The upper and lower epidermis were composed of one layer of regular long polygonal cells, arranged closely. The stomatal apparatus was only located in the lower epidermis and was composed of two guard cells. Epidermal cell quantitative characteristics were different between the two cultivars and in different parts of the leaf (Table 1). The epidermal cells in C. capense var. medio-pictum were larger than those in $C$. capense, and both upper and lower epidermal cells in the leaf center were bigger than those at the leaf edge. In the same part, the upper epidermal cells were bigger than the lower epidermal cells. The upper and lower epidermal cells in YS were larger than those in GS, GC, and GE. It should be noted that the block of Chl biosynthesis in the mesophyll cells of YS did not inhibit chloroplast biogenesis of the guard cells, and $\mathrm{Chl}$ fluorescence and chloroplasts can be detected in the guard cells (Fig. 6). The stomatal size of the leaf center was 83 and $68 \%$ smaller than the leaf edge in C. capense var. medio-pictum and C. capense, respectively (Table 2). Within the same leaf zone, the stomatal size of $C$. capense var. medio-pictum was bigger than that of C. capense. The stomatal index in the yellowish white leaf stripes was about 1.2 times higher than that in the other parts. Overall, these results clearly showed that epidermal and stomatal development was significantly altered in the Chl-less YS part. 

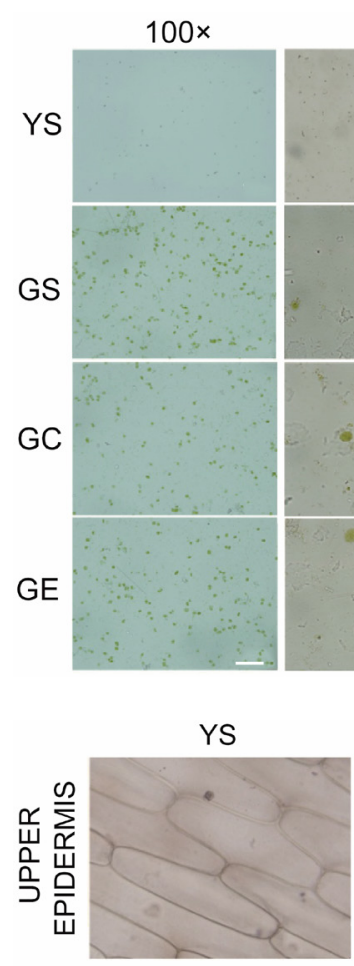

虽号品
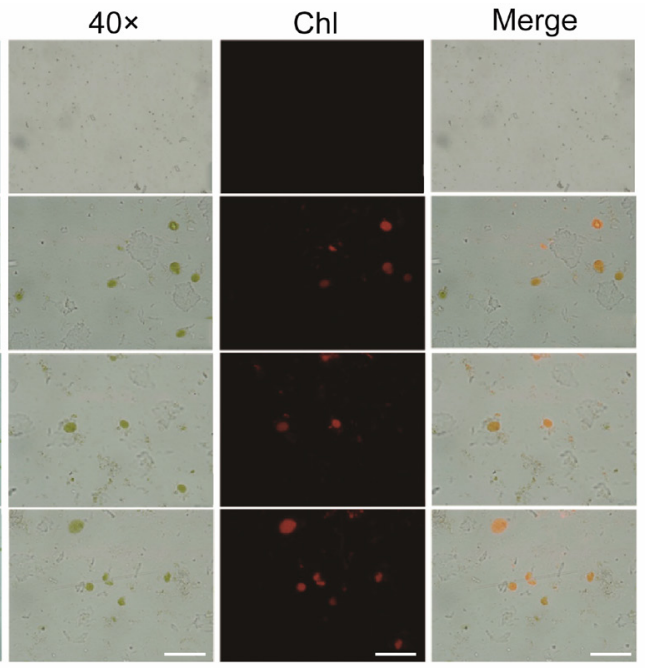

Fig. 4. The chloroplasts of mesophyll in different parts of Chlorophytum capense var. medio-pictum and C. capense leaves. YS - yellowish white leaf stripe; GS - green leaf stripe; GC - green leaf center; GE - green leaf edge. White scale bar of $100 \times$ represents $50 \mu \mathrm{m}$ and white scale bars of others represent $20 \mu \mathrm{m}$.
GS
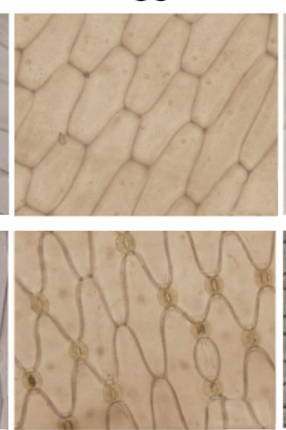

GC
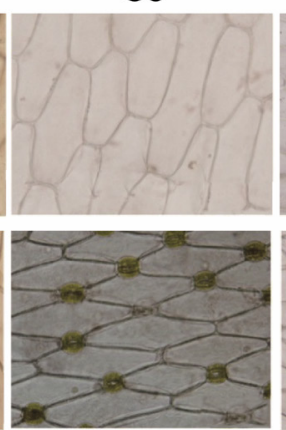

GE

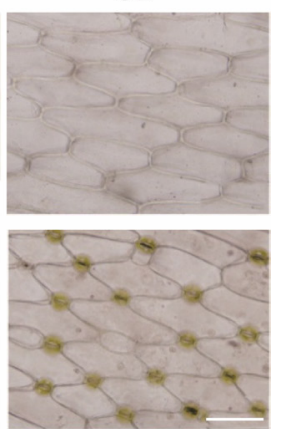

Fig. 5. The epidermis from different parts of Chlorophytum capense var. medio-pictum and C.capense leaves. YS - yellowish white leaf stripe; GS green leaf stripe; GC - green leaf center; GE - green leaf edge. White scale bar represents $100 \mu \mathrm{m}$.

Table 1. The epidermal cell characteristics of Chlorophytum capense var. medio-pictum and C. capense leaves. Values are expressed as mean \pm standard deviation $(n=3)$, different letters denote significant differences $(p<0.05)$. YS - yellowish white leaf stripe; GS - green leaf stripe; GC - green leaf center; GE - green leaf edge.

\begin{tabular}{|c|c|c|c|c|c|}
\hline \multicolumn{2}{|c|}{ Leaf type } & \multirow{2}{*}{$\frac{\text { Cell length }[\mu \mathrm{m}]}{252.31 \pm 26.03^{\mathrm{a}}}$} & \multirow{2}{*}{$\begin{array}{l}\text { Cell width }[\mu \mathrm{m}] \\
67.88 \pm 4.62^{\mathrm{a}}\end{array}$} & \multirow{2}{*}{$\begin{array}{l}\text { Cell size }\left[\mu \mathrm{m}^{2}\right] \\
8376.11 \pm 902.67^{\mathrm{a}}\end{array}$} & \multirow{2}{*}{$\frac{\text { Cell number }\left[\mathrm{mm}^{-2}\right]}{28.47 \pm 1.49^{\mathrm{d}}}$} \\
\hline YS & Upper epidermis & & & & \\
\hline & Lower epidermis & $208.27 \pm 24.97^{\mathrm{cd}}$ & $34.14 \pm 5.47^{c}$ & $4311.27 \pm 316.11^{\mathrm{c}}$ & $49.86 \pm 4.90^{\mathrm{b}}$ \\
\hline \multirow[t]{2}{*}{ GS } & Upper epidermis & $219.57 \pm 22.14^{b}$ & $68.81 \pm 7.11^{\mathrm{a}}$ & $6095.03 \pm 610.67^{b}$ & $68.49 \pm 7.69^{c}$ \\
\hline & Lower epidermis & $185.86 \pm 19.95^{\mathrm{e}}$ & $43.01 \pm 3.68^{b}$ & $3883.36 \pm 212.51^{\mathrm{d}}$ & $82.25 \pm 7.23^{\mathrm{f}}$ \\
\hline \multirow[t]{2}{*}{$\mathrm{GC}$} & Upper epidermis & $203.08 \pm 12.65^{\mathrm{d}}$ & $67.30 \pm 6.39^{\mathrm{a}}$ & $4875.00 \pm 471.33^{c}$ & $50.11 \pm 5.02^{\mathrm{b}}$ \\
\hline & Lower epidermis & $179.28 \pm 27.76^{\mathrm{e}}$ & $44.33 \pm 3.71^{\mathrm{b}}$ & $3041.31 \pm 183.50^{\mathrm{e}}$ & $74.46 \pm 9.91^{\mathrm{a}}$ \\
\hline \multirow[t]{2}{*}{ GE } & Upper epidermis & $196.67 \pm 19.58^{c}$ & $68.96 \pm 7.78^{a}$ & $4007.24 \pm 246.56^{\mathrm{d}}$ & $84.24 \pm 4.98^{\mathrm{a}}$ \\
\hline & Lower epidermis & $164.33 \pm 13.29^{\mathrm{f}}$ & $41.74 \pm 6.23^{b}$ & $2693.00 \pm 179.75^{\mathrm{f}}$ & $100.34 \pm 10.23^{\mathrm{e}}$ \\
\hline
\end{tabular}

\section{Discussion}

Studies on the mechanism of the formation of variegated leaves have made considerable progress in recent years. Genotypic characteristics, somatic mutations, and viral infections are thought to be the major reasons causing variegation of leaves (Zhang et al. 2018). Mutant plants, var1 and var2, display variegated leaves due to the absence of FtsH metalloproteases, which are responsible for degrading chloroplast proteins (Kato et al. 2012).
The immutans mutant has green and white variegated leaves because of the loss of function of the plastid terminal oxidase (PTOX) (Foudree et al. 2012). A large number of studies indicated that the phenotypes of variegated leaves are closely associated with chloroplast biogenesis, and Chl biosynthesis is necessary for the assembly of the photosynthetic apparatus during chloroplast biogenesis.

Chl biosynthesis takes place in chloroplasts and shares common intermediates with other tetrapyrroles including siroheme, heme, and phytochromobilin. Multiple environmental factors, such as light (Ilag et al. 1994, Oosawa et al. 


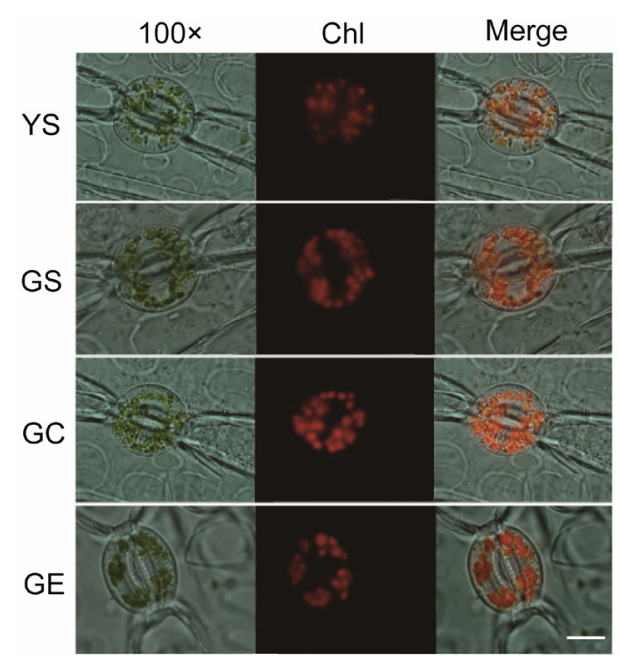

Fig. 6. The stomatal characteristic in different parts of Chlorophytum capense var. medio-pictum and $C$. capense leaves. YS yellowish white leaf stripe; GS - green leaf stripe; GC - green leaf center; GE - green leaf edge. White scale bar represents $20 \mu \mathrm{m}$.

2000, Meskauskiene et al. 2001, Cornah et al. 2003), temperature (Nagata et al. 2005), and nutrient (Tanaka and Tanaka 2007) could regulate Chl biosynthesis. The two pivotal control points of the $\mathrm{Chl}$ biosynthesis pathway are the formation of the initial precursor ALA, and the metalion insertion step: chelation of $\mathrm{Fe}^{2+}$ into Proto IX that leads to heme and phytochromobilin, whereas the insertion of $\mathrm{Mg}^{2+}$ is the first step branched toward the formation of Chls (Cornah et al. 2003). ALA synthesis, acting as a ratelimiting step, is the first and foremost point of tetrapyrrole biosynthesis pathway that controls the total fluxes. Its synthesis appears to be feedback inhibited by heme and modulated by the FLU protein through the glutamyl-tRNA reductase (Cornah et al. 2003). In this study, except for the accumulation of Coprogen III and Mpe, other precursors were all lower in the yellowish white leaf stripes than that of the green parts, especially the ALA content, which was $50 \%$ lower than that of the green parts (Fig. 2). Our data demonstrated that the tetrapyrrole pathway appears to be inhibited at the ALA synthesis step. Coprogen III and Mpe were highly accumulated in YS. But their downstream products, Proto IX and Pchlide, were very low in YS, suggesting that the conversions from Coprogen III to Proto IX and from Mpe to Pchlide might be inhibited. The conversion from Coprogen III to Proto IX was catalyzed by coproporphyrinogen III oxidase and protoporphyrinogen IX oxidase, while the conversion from Mpe to Pchlide was catalyzed by $\mathrm{Mg}$-protoporphyrin monomethyl ester cyclase. Therefore, the activities of coproporphyrinogen III oxidase, protoporphyrinogen IX oxidase, and Mg-protoporphyrin monomethyl ester cyclase might also be control points and limit the Chl metabolic flux in YS. Therefore, we presume that the suppression of ALA synthesis might be the main reason for the yellowish white leaf stripes phenotype of $C$. capense var. medio-pictum. At the same time, the lower conversion efficiencies from Coprogen III to Proto IX and from Mpe to Pchlide may also have a role in the formation of the yellowish white leaf stripes.

YS accumulated very low amount of Chls and showed a high ratio of Car to Chls, which was consistent with the data from the golden-leaf privet (Yuan et al. 2010). And another study on 14 kinds of golden-leaf plants found that all these golden-leaf plants contained less $\mathrm{Chl}$ and showed relatively high Car content (Hu et al. 2007). It is well known that Car are responsible for harvesting solar energy and photoprotection during photosynthesis. $\mathrm{F}_{\mathrm{v}} / \mathrm{F}_{\mathrm{m}}$ and NPQ were slightly lower in the YS part compared to those in the green parts (Fig. 1S). Similar results have been also observed in some other variegated leaves of Coleus $\times$ hybridus hort. cultivars, Hedera helix, Ardisia pusilla, and Scindapsus aureus (Khalekuzzaman et al. 2015, Borek et al. 2016). According to the Chl fluorescence data, YS retained high $F_{v} / F_{m}$ values, suggesting that high Car in YS might be responsible for harvesting light energy. Meanwhile, Borek et al. (2016) showed that higher Car in purple parts of Coleus $\times$ hybridus hort. cultivars could provide photoprotective effects. Our previous study demonstrated that NPQ in YS increased under high light (Dong et al. 2015). This phenomenon might be due to the accelerated xanthophyll cycle and the increased thermal dissipation. Thus, higher Car might play an important role in photoprotection under high light.

Leaf pigments may regulate the physiological performance of leaves and the leaf structure (Sims and Gamon 2002). In golden-leaf privet, the upper golden leaves and the lower green leaves showed a different pigment content, which was closely connected to their leaf structures and epidermis development (Yuan et al. 2014). In addition, our previous study showed that blocked $\mathrm{Chl}$ biosynthesis and chloroplast development perhaps restrained the size of the mesophyll cells (Jia et al. 2011). In the present study, the epidermis cell size in YS was significantly larger than that

Table 2. The stomata characteristics of Chlorophytum capense var. medio-pictum and $C$. capense leaves. Values are expressed as mean \pm standard deviation $(n=3)$, different letters denote significant differences $(p<0.05)$. YS - yellowish white leaf stripe; GS - green leaf stripe; GC - green leaf center; GE - green leaf edge.

\begin{tabular}{llllll}
\hline Leaf type & Stomata length $[\mu \mathrm{m}]$ & Stomata width $[\mu \mathrm{m}]$ & Stomata size $\left[\mu \mathrm{m}^{2}\right]$ & Stomata density $\left[\mathrm{mm}^{-2}\right]$ & Stomatal index \\
\hline YS & $35.76 \pm 2.20^{\mathrm{ab}}$ & $30.19 \pm 2.80^{\mathrm{a}}$ & $423.73 \pm 20.08^{\mathrm{b}}$ & $129.11 \pm 11.80^{\mathrm{d}}$ & $72.14 \pm 6.69^{\mathrm{a}}$ \\
GS & $39.27 \pm 3.49^{\mathrm{a}}$ & $32.91 \pm 2.90^{\mathrm{a}}$ & $507.27 \pm 35.34^{\mathrm{a}}$ & $189.74 \pm 15.43^{\mathrm{b}}$ & $59.76 \pm 4.46^{\mathrm{b}}$ \\
GC & $30.49 \pm 2.27^{\mathrm{c}}$ & $24.85 \pm 3.33^{\mathrm{bc}}$ & $295.97 \pm 10.66^{\mathrm{c}}$ & $158.21 \pm 17.30^{\mathrm{c}}$ & $58.00 \pm 7.80^{\mathrm{b}}$ \\
GE & $37.82 \pm 2.82^{\mathrm{a}}$ & $29.68 \pm 1.93^{\mathrm{ab}}$ & $432.20 \pm 25.14^{\mathrm{b}}$ & $217.67 \pm 18.96^{\mathrm{a}}$ & $58.45 \pm 6.04^{\mathrm{b}}$ \\
\hline
\end{tabular}


of the other parts (Table 1). Stomata are the portals for gas exchange between the mesophyll cells and the environment (Driscoll et al. 2006). In C. capense var. medio-pictum leaves, Chl biosynthesis was seriously blocked and no chloroplasts were detected in YS mesophyll, but the stomata development in the lower epidermis was normal and the guard cells had typical chloroplasts (Fig. 6). However, the stomatal density was reduced significantly in YS. It is an interesting phenomenon that the stomatal guard cells retain photosynthetically active chloroplasts. Zhang et al. (2018) also detected strong Chl fluorescence in the lower epidermis of the yellow parts of variegated Aucuba japonica 'Variegata' leaves (Zhang et al. 2018). Chloroplasts in the stomatal guard cells might be important for regulating the opening and closing of the stomata to control gas and moisture exchanges between the plant and the external atmosphere. Additionally, the presence of a low amount of Chls (Fig. 1B) and photosynthetic proteins (Fig. $3 B, C$ ) in YS might be due to the presence of chloroplasts in the guard cells of the lower epidermis.

C. capense var. medio-pictum is an ideal material to study chlorophyll metabolism, chloroplast biogenesis, and leaf development because of its unique phenotype and leaf structure. Interestingly, there was no chlorophyll in the mesophyll cells, while the stomata possess normal chloroplasts and chlorophyll. Therefore, the interrelations between the epidermal and mesophyll cells during development and the mechanism of chlorophyll synthesis and plastid biogenesis need further investigation.

\section{References}

Beale S.I.: Green genes gleaned. - Trends Plant Sci. 10: 309-312, 2005.

Berger D., Altmann T.: A subtilisin-like serine protease involved in the regulation of stomatal density and distribution in Arabidopsis thaliana. - Gene. Dev. 14: 1119-1131, 2000.

Borek M., Bączek-Kwinta R., Rapacz M.: Photosynthetic activity of variegated leaves of Coleus $\times$ hybridus hort. cultivars characterised by chlorophyll fluorescence techniques. Photosynthetica 54: 331-339, 2016.

Bradford M.M.: Rapid and sensitive method for quantification of microgram quantities of protein utilizing principle of proteindye-binding. - Anal. Biochem. 72: 248-254, 1976.

Chen Y., Asano T., Fujiwara M.T. et al.: Plant cells without detectable plastids are generated in the crumpled leaf mutant of Arabidopsis thaliana. - Plant Cell Physiol. 50: 956-969, 2009.

Chen Y.E., Liu W.J., Su Y.Q. et al.: Different response of photosystem II to short and long term drought stress in Arabidopsis thaliana. - Physiol. Plantarum 158: 225-235, 2016.

Cornah J.E., Terry M.J., Smith A.G.: Green or red: what stops the traffic in the tetrapyrrole pathway? - Trends Plant Sci. 8: 224-230, 2003

Dong L.H., Han Q.H., Yang Y., Yuan M.: [Photosynthetic characteristics of Chlorophytum capense var. medio-pictum under short duration high light intensity.] - Acta Pratacult. Sin. 24: 245-252, 2015. [In Chinese]

Driscoll S.P., Prins A., Olmos E. et al.: Specification of adaxial and abaxial stomata, epidermal structure and photosynthesis to $\mathrm{CO}_{2}$ enrichment in maize leaves. - J. Exp. Bot. 57: 381-390, 2006
Foudree A., Putarjunan A., Kambakam S. et al.: The mechanism of variegation in immutans provides insight into chloroplast biogenesis. - Front. Plant Sci. 3: 260, 2012.

Fristedt R., Granath P., Vener A.V.: A protein phosphorylation threshold for functional stacking of plant photosynthetic membranes. - PLoS ONE 5: e10963, 2010.

Horiguchi G., Fujikura U., Ferjani A. et al.: Large-scale histological analysis of leaf mutants using two simple leaf observation methods: identification of novel genetic pathways governing the size and shape of leaves. - Plant J. 48: 638-644, 2006.

Hu H.Z., Zhang R., Shang A.Q. et al.: [Response of pigment content of golden leaf plants to light intensity.] - Acta Hortic. Sin. 3: 717-722, 2007. [In Chinese]

Ilag L.L., Kumar A.M., Söll D.: Light regulation of chlorophyll biosynthesis at the level of 5-aminolevulinate formation in Arabidopsis. - Plant Cell 6: 265-275, 1994.

Jia X.J., Dong L.H., Ding C.B. et al.: [Effects of drought stress on reactive oxygen species and their scavenging systems in Chlorophytum capense var. medio-pictum leaf.] - Acta Pratacult. Sin. 22: 248-255, 2013. [In Chinese]

Jia X.J., Ran H.C., Zeng S.H. et al.: [Study on leaf anatomical structure of Chlorophytum capense var. medio-pictum.] J. Sichuan Agric. Univ. 29: 199-202, 2011. [In Chinese]

Jung K.H., Hur J., Ryu C.H. et al.: Characterization of a rice chlorophyll-deficient mutant using the T-DNA gene-trap system. - Plant Cell Physiol. 44: 463-472, 2003.

Kato Y., Kouso T., Sakamoto W.: Variegated tobacco leaves generated by chloroplast FtsH suppression: Implications of FtsH function in the maintenance of thylakoid membranes. Plant Cell Physiol. 53: 391-404, 2012.

Khalekuzzaman M.D., Kim K.J., Kim H.J. et al.: Comparison of green and variegated foliage plant species based on chlorophyll fluorescence parameters under different light intensities. - Pak. J. Bot. 47: 1709-1715, 2015.

Lichtenthaler H., Wellburn A.: Determination of total carotenoids and chlorophylls $a$ and $b$ of leaf in different solvents. Biochem. Soc. T. 11: 591-592, 1983.

Liu Z.L., Yuan S., Liu W.J. et al.: Mutation mechanism of chlorophyll-less barley mutant NYB. - Photosynthetica 46: 73-78, 2008.

Masuda T., Fujita Y.: Regulation and evolution of chlorophyll metabolism. - Photoch. Photobio. Sci. 7: 1131-1149, 2008.

Meskauskiene R., Nater M., Goslings D. et al.: FLU: A negative regulator of chlorophyll biosynthesis in Arabidopsis thaliana.P. Natl. Acad. Sci. USA 98: 12826-12831, 2001.

Nagata N., Tanaka R., Satoh S., Tanaka A.: Identification of a vinyl reductase gene for chlorophyll synthesis in Arabidopsis thaliana and implications for the evolution of Prochlorococcus species. - Plant Cell 17: 233-240, 2005.

Nakanishi H., Nozue H., Suzuki K. et al.: Characterization of the Arabidopsis thaliana mutant $p c b 2$ which accumulates divinyl chlorophylls. - Plant Cell Physiol. 46: 467-473, 2005.

Oosawa N., Masuda T., Awai K. et al.: Identification and light-induced expression of a novel gene of NADPHprotochlorophyllide oxidoreductase isoform in Arabidopsis thaliana. - FEBS Lett. 474: 133-136, 2000.

Plumley F.G., Schmidt G.W.: Light-harvesting chlorophyll $a / b$ complexes: Interdependent pigment synthesis and protein assembly. - Plant Cell 7: 689-704, 1995.

Porra R.J., Thompson W.A., Kriedemann P.E.: Determination of accurate extinction coefficients and simultaneous equations for assaying chlorophylls $a$ and $b$ extracted with four different solvents: Verification of the concentration of chlorophyll standards by atomic absorption spectroscopy. BBA-Bioenergetics 975: 384-394, 1989. 
Rüdiger W.: Biosynthesis of chlorophyll $b$ and the chlorophyll cycle. - Photosynth. Res. 74: 187-193, 2002.

Sims D.A., Gamon J.A.: Relationships between leaf pigment content and spectral reflectance across a wide range of species, leaf structures and developmental stages. - Remote Sens. Environ. 81: 337-354, 2002.

Smith A.G., Witty M.: Heme, Chlorophyll, and Bilins. Methods and Protocols. Pp. 340. Humana Press, Torowa 2002.

Tanaka A., Tanaka R.: Chlorophyll metabolism. - Curr. Opin. Plant Biol. 9: 248-255, 2006.

Tanaka R., Tanaka A.: Tetrapyrrole biosynthesis in higher plants. Annu. Rev. Plant Biol. 58: 321-346, 2007.

Yuan M., Dong L.H., Jia X.J. et al.: [Effects of canopy position on leaf structures in golden-leaf privet (Ligustrum $\times$ vicaryi).] Bull. Bot. Res. 34: 188-193, 2014. [In Chinese]
Yuan M., Xu M.Y., Yuan S. et al.: Light regulation to chlorophyll synthesis and plastid development of the chlorophyll-less golden-leaf privet. - J. Integr. Plant Biol. 52: 809-816, 2010.

Yuan M., Zhao Y.Q., Zhang Z.W. et al.: Light regulates transcription of chlorophyll biosynthetic genes during chloroplast biogenesis. - Crit. Rev. Plant Sci. 36: 35-54, 2017.

Zhang H., Li J., Yoo J.H. et al.: Rice Chlorina-1 and Chlorina-9 encode ChlD and ChlI subunits of Mg-chelatase, a key enzyme for chlorophyll synthesis and chloroplast development. Plant Mol. Biol. 62: 325-337, 2006.

Zhang Q., Zhang M., Ding Y.et al.: Composition of photosynthetic pigments and photosynthetic characteristics in green and yellow sectors of the variegated Aucuba japonica 'Variegata' leaves. - Flora 240: 25-33, 2018.

(C) The authors. This is an open access article distributed under the terms of the Creative Commons BY-NC-ND Licence. 